\title{
Um aplicativo para a aprendizagem do protocolo Advanced Cardiovascular Life Support
}

Julio Didier Maciel, Universidade Federal de Itajubá, juliodidier@gmail.com Rodrigo Duarte Seabra, Universidade Federal de Itajubá, rodrigo@unifei.edu.br Rodrigo M. A. de Almeida, Universidade Federal de Itajubá, rmaalmeida@ gmail.com

Resumo: Esta pesquisa visa apresentar um aplicativo para apoiar o ensino e a execução do protocolo Advanced Cardiovascular Life Support - ACLS, em ambientes hospitalares, elaborado pela American Heart Association, principal associação de pesquisas cardíacas do mundo. Após seu desenvolvimento, o aplicativo foi testado com um grupo de estudantes voluntários. Por meio da aplicação do modelo Technology Acceptance Model, que utiliza dois critérios de avaliação da aceitação da tecnologia pautados pela utilidade percebida e facilidade de uso percebida, verificou-se que os resultados da simulação utilizando a ferramenta foram positivos, revelando indícios de que o aplicativo proposto foi eficaz em sua função de auxílio à execução do protocolo ACLS.

Palavras-chave: aplicativo, aprendizagem, protocolo ACLS.

\section{An Application for Learning the Advanced Cardiovascular Life Support Protocol}

Abstract: This research aims to present an application to support the teaching and execution of the Advanced Cardiovascular Life Support protocol - ACLS, in hospital environments, prepared by the American Heart Association, the world's leading cardiac research association. After its development, the app was tested with a group of student volunteers. Through the application of the Technology Acceptance Model, which uses two criteria for assessing technology acceptance based on perceived utility and perceived ease of use, it was found that the simulation results using the tool were positive, revealing evidence that the application proposed was effective in assisting the implementation of the ACLS protocol.

Keywords: application, learning, ACLS protocol.

\section{INTRODUÇÃO}

A parada cardíaca, ou parada cardiorrespiratória (PCR), é a perda abrupta da função cardíaca em uma pessoa que pode ou não ter diagnosticado doença cardíaca. Para os casos em que ocorrem o óbito, o tempo e o modo deste são inesperados, verificando-se instantaneamente ou logo após o aparecimento dos sintomas (ABOUT..., 2017). Mesmo sem saber se o indivíduo está sofrendo um ataque cardíaco, é aconselhado que o serviço de tratamento de urgência (bombeiros, ambulância ou hospital) seja acionado imediatamente. Esta prestação de socorro deve seguir instruções da American Heart Association - AHA (AMERICAN..., 2015) e, no caso de uma pessoa leiga, recomenda-se o uso do protocolo Basic Life Support - BLS, que é uma forma simplificada de primeiros socorros. Todavia, além do BLS, o principal modo de tratamento da PCR é a forma avançada do BLS, denominada Advanced Cardiovascular Life Support - ACLS, objeto de estudo desta pesquisa.

Apesar de o protocolo ACLS ser o processo mais adequado a se realizar no caso de uma ressuscitação cardiopulmonar (RCP), ressalta-se que o despreparo e a falta de 
treinamento de alguns médicos são problemas frequentes (KURRCK et al., 1998; ISBYE et al., 2007). Nesse sentido, Hayes et al. (2007) demonstraram que praticamente metade dos 289 residentes que responderam a uma pesquisa realizada, afirmaram se sentir despreparados para liderar o processo de RCP durante a ocorrência de uma PCR. $\mathrm{O}$ estudo mostrou que nem todos os profissionais são treinados com os padrões estipulados pelo protocolo da AHA. De maneira semelhante, o estudo de Dane et al. (2000) defende que um paciente que sofreu uma PCR tem quatro vezes mais chance de sobrevivência se atendido por enfermeiros que tiveram treinamento do ACLS.

Para a execução correta das etapas envolvidas no protocolo ACLS e considerando ainda seus respectivos períodos estipulados é necessário que haja um assistente responsável somente para esta tarefa de controle durante o processo de ressuscitação. Com base na execução do protocolo e utilizando as informações do ACLS, é possível elaborar uma forma automatizada para se controlar as etapas, auxiliando a realização do processo e monitorando o tempo de cada etapa executada.

O estudo em tela se justifica devido a alguns fatores: (i) anualmente, em todo o mundo há mais de 135 milhões de mortes relacionadas ao acidente cardiovascular e a prevalência de doenças coronárias tem crescido (MEANEY et al., 2013); (ii) nos ambientes não hospitalares, o número de pessoas que sofrem PCRs e que não são prontamente socorridas é três vezes maior do que as que são atendidas por serviços médicos especializados (RINGH et al., 2011); (iii) no ambiente hospitalar, apesar de se dispor de ferramentas e recursos humanos, o processo de ressuscitação requer extrema atenção e esforço físico daqueles que o executam, se tornando cansativo, estressante e, sobretudo, arriscado; (iv) o protocolo ACLS é, atualmente, a técnica mais utilizada pelos profissionais da saúde (BROOKS et al., 2015).

Com base no exposto, esta pesquisa tem como objetivo apresentar um aplicativo para smartphones visando apoiar o aprendizado e a execução do protocolo ACLS. Como contribuição direta do estudo espera-se que haja uma diminuição no índice de óbitos decorrentes de paradas cardiorrespiratórias. Ainda no escopo desta pesquisa, tendo em vista que seu público alvo é composto por médicos residentes, estudantes de medicina, médicos e enfermeiros responsáveis por atendimentos em prontos-socorros, após o desenvolvimento do aplicativo proposto, a ferramenta foi disponibilizada a um grupo de participantes voluntários que avaliaram sua percepção de uso com base no modelo Technology Acceptance Model - TAM (DAVIS et al., 1989).

\section{REFERENCIAL TEÓRICO}

Atualmente, o uso de aparelhos celulares, principalmente, smartphones, encontra-se difundido na sociedade em todas as esferas, sejam elas pessoais ou profissionais, em razão das mais variadas necessidades (DINH et al., 2013). Este dispositivo desenvolvido para servir como mais um meio de comunicação, hoje é usado para diversas outras funções, inclusive no apoio ao aprendizado de novos conhecimentos. Globalmente, os celulares estão interconectando usuários de diversas regiões e esta interação permite uma habilidade imprescindível para comunicação relacionada à saúde, aplicativos para monitoramento e auxílio de doenças e melhora de comunicação entre pacientes, médicos e enfermeiros (SIEGEL et al., 2016). Ademais, a partir de seus benefícios e facilidade de acesso, os aplicativos móveis são cada vez mais utilizados por diferentes perfis de usuários, inclusive por pessoas de distintas classes sociais (SONG et al., 2014).

Recentemente, devido à praticidade, custo e propagação dos dispositivos móveis, houve um crescimento relevante no desenvolvimento de aplicativos 
relacionados à saúde, que reduzem e facilitam o trabalho de seus usuários. Apesar disso, esses aplicativos ainda não são muito utilizados devido à falta de divulgação, fazendo com que a área de mHealth (mobile health) ainda se encontre em crescimento e seja alvo de estudos e de iniciativas de desenvolvimento da área (LIANG et al., 2011, BARBOSA et al. 2018, SANTOS et al., 2019). Uma das aplicações que atualmente não se tem conhecimento na literatura é o uso de aplicativos que auxiliem em todo o processo de ressuscitação cardiopulmonar, via protocolo ACLS, decorrente de uma parada cardiorrespiratória.

O protocolo ACLS é mais complexo do que o BLS. Este último pode ser executado por leigos, sendo que no ACLS é necessário o acesso a drogas injetáveis e o procedimento deve ser conduzido por uma equipe médica, normalmente dentro de um ambiente hospitalar. De forma geral, o ACLS, seguindo as diretrizes da AHA (HAZINSKI; FIELD, 2010), envolve questões sobre: oxigenação por vias aéreas, monitoramento fisiológico e prognóstico durante a PCR, desfibrilação, drogas antiarrítmicas e vasopressores. As massagens cardíacas devem ser realizadas da mesma maneira que no protocolo BLS, de 100 a 120 vezes por minuto. As aberturas das vias respiratórias devem ser conduzidas por meio de um aparelho especializado, que, após instalado no paciente, deve ser ativado em um intervalo de seis a oito segundos.

\subsection{Trabalhos Correlatos}

No que tange a aplicativos relacionados à RCP e à PCR, não foram encontrados trabalhos sistematicamente relatados na literatura, muito menos qualquer abordagem relativa ao ensino dos procedimentos envolvidos em um ambiente controlado, dada sua complexidade, utilizando ferramentas computacionais. As pesquisas realizadas identificaram apenas alguns aplicativos com objetivos semelhantes ao desta pesquisa nas lojas virtuais App Store e Play Store, porém, incompletos.

Como um dos exemplos, o aplicativo "Real Time CPR Guide", disponível na Play Store, auxilia a execução do protocolo BLS com vídeos e sons para conduzir o usuário a realizar as tarefas do protocolo. A maneira como o aplicativo age sobre o usuário é diferente da proposta nesta pesquisa, uma vez que o aplicativo em questão serve mais como uma forma ilustrada dos passos envolvidos na execução do protocolo. Similarmente, o aplicativo "CPR Helper", disponível na App Store, ilustra, com fotos, as etapas de como deve ser executada a ressuscitação em um paciente utilizando o protocolo BLS. O aplicativo "CPR tempo" está relacionado ao auxílio da execução do protocolo ACLS, assim como no estudo em tela. Este aplicativo faz a tarefa do metrônomo e contabiliza o intervalo de aplicação da adrenalina. Contudo, o aplicativo não traz as demais funções necessárias para o protocolo ACLS.

Foram encontrados ainda aplicativos que realizam testes e simulam casos clínicos, elaborando questões e ensinando o usuário a como se portar em situações diferentes. Os aplicativos "Ressuscitation" e "ACLS 2015 American Hrt Guidelines", disponíveis na App Store, têm o objetivo de avaliar estudantes com questões relacionadas ao curso de Medicina. O primeiro oferece um "ranking", proporcionando uma ideia de competição e diversão para os usuários. Entretanto, nenhuma abordagem de uso prática foi encontrada.

Nota-se que existem aplicativos relacionados à PCR disponíveis nas lojas virtuais. Apesar de estarem relacionados com situações nas quais o BLS ou o ACLS são aplicados, seus objetivos diferem do proposto nesta pesquisa, pois eles não auxiliam a execução do protocolo ou o fazem de forma incompleta, sendo específicos para apenas partes do protocolo, o que, mais uma vez, justifica a realização deste estudo. 


\section{MÉTODO}

\subsection{O Aplicativo Stay Alive}

O aplicativo proposto, denominado Stay Alive, visa apoiar o atendimento de uma PCR, que representa um momento crítico em um atendimento de emergência. Partindo dessa premissa, suas funções devem ser executadas o mais rápido possível. Ao iniciar o aplicativo, o botão de iniciar PCR já se encontra disponível, já que esta é a principal função do aplicativo. As demais funções são disponibilizadas em telas adicionais, sendo acessadas por botões com ícones menores posicionados na tela inicial. Os requisitos do aplicativo foram levantados a partir de uma entrevista com um médico experiente na execução do protocolo ACLS, com perfil representativo dos potenciais usuários.

A partir das informações coletadas, verificou-se a necessidade de implementação de sete funcionalidades para o auxílio durante uma PCR, sendo todas aprovadas pelo médico responsável pelos requisitos, a saber: (i) tela de suporte - contendo informações de contato com o desenvolvedor; (ii) questionário sobre dados da parada após a finalização do processo - contendo as prováveis causas para a ocorrência da PCR e seu resultado final (óbito ou RCE); (iii) relatório final - apresenta o relatório da PCR ocorrida com dados e ações tomadas na PCR; (iv) armazenamento em nuvem - dados gerados em nuvem para estudos posteriores; (v) tela para alteração dos dados durante a PCR - devido à necessidade de modificação de alguns dados de acordo com as diretrizes da AHA; (vi) modos diferentes de uso - direcionados a profissionais mais experientes, no primeiro caso, e o outro deverá atender a profissionais menos experientes, residentes e acadêmicos que ainda estejam em fase de estudos do protocolo ACLS e da condução de uma PCR; (vii) tutorial - conduzirá o usuário a realizar as funções básicas na tela principal de uma PCR, abrangendo suas principais situações, como alteração de ritmos cardíacos, aplicação de drogas, desfibrilações etc.

O aplicativo foi desenvolvido para as plataformas iOS e Android, oferecendo duas opções de idiomas: português e inglês. No caso da primeira plataforma, utilizou-se a linguagem Swift e, para a segunda, a linguagem Java. Algumas telas do aplicativo estão ilustradas na Figura 1.

(a)

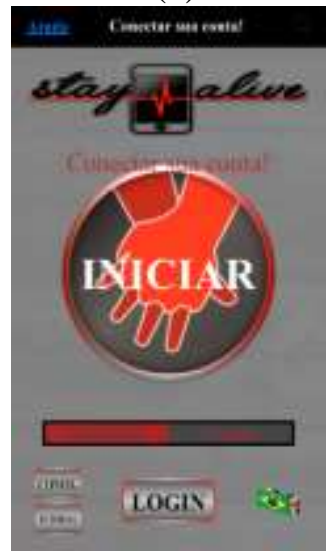

(b)

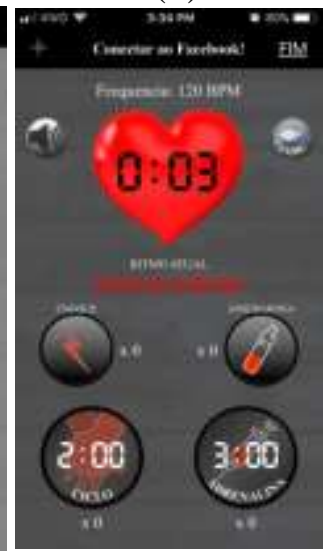

(c)

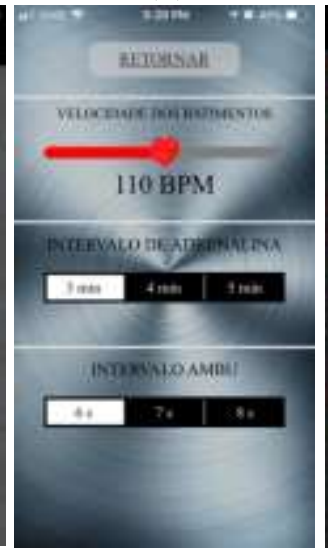

(d)

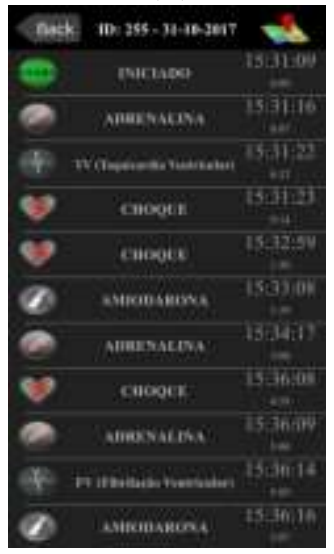

Figura 1 - Interface do aplicativo Stay Alive. Fonte: Os autores.

A tela inicial do aplicativo (Figura 1a) possui variados botões para acesso a mais informações, tutorial, alteração de idioma, $\operatorname{login}$ e, em destaque no centro da tela, há o botão de início da PCR, que tem como objetivo levar o usuário à tela de auxílio da PCR (Figura 1b). Nesta tela, há todas as ferramentas necessárias para a condução de uma V. $17 \mathrm{~N}^{\circ}$ 3, dezembro, 2019 RENOTE DOI: 
RCP seguindo o protocolo ACLS. É possível alterar o ritmo cardíaco, acrescentar a quantidade de desfibrilações e de amiodarona aplicados, reiniciar a contagem e acrescentar a quantidade de ciclos de compressões e adrenalinas. De acordo com a Figura 1c, é possível alterar as configurações de frequência de compressões e os intervalos de aplicação da adrenalina e ventilação do paciente por meio do AMBU. Ao finalizar a condução da PCR, o relatório final é emitido ao usuário contendo os horários de aplicação de cada item (Figura 1d). Este relatório também é possível ser acessado, posteriormente, via histórico do aplicativo.

\subsection{Participantes e Descrição do Método}

Após o desenvolvimento do aplicativo, foram realizados testes de uso em um ambiente mais próximo possível da realidade, a fim de proporcionar maior confiabilidade aos resultados observados. Os testes contaram com o envolvimento de oito participantes voluntários, sendo todos estudantes matriculados regularmente no quinto ano do curso de Medicina da Faculdade de Medicina de Itajubá. Estes participantes foram responsáveis por interagir com o aplicativo durante a execução do teste, além de responderem os questionários pré e pós-teste e conduzirem a execução de cada teste. Da mesma maneira, foram utilizados três atores, também voluntários, para conduzirem as ações do processo de ressuscitação cardiopulmonar, tais como realizar as compressões torácicas em um manequim robótico, simular a aplicação de drogas e ventilações e checar o pulso do paciente, no caso, do manequim. Os atores participaram de todos os testes. Um texto de orientação foi elaborado para a apresentação e melhor explicação da condução dos testes. Além deste, um termo de consentimento também foi confeccionado com o intuito de comunicar os participantes sobre o objetivo do teste.

Os testes foram conduzidos no Laboratório de Usabilidade da Universidade Federal de Itajubá e contaram com a participação de um manequim robótico SimMan3G, deitado em uma maca, com o monitor cardíaco acoplado em seu corpo. Detalhes adicionais sobre o funcionamento do manequim podem ser encontrados em Maciel et al. (2019). Foi determinado o prazo máximo de 10 minutos para a finalização de cada teste. Caso o participante não finalizasse todas as atividades antes desse prazo, o teste era interrompido e dado como finalizado, tendo suas ações analisadas somente até esse momento. Para todos os participantes, inclusive os atores, foi ministrado um curso preparatório, ministrado pelo primeiro autor deste trabalho, sobre o protocolo ACLS e a ocorrência de uma PCR. O curso tratou os principais conceitos envolvidos no processo de ressuscitação. Para cada participante, o teste foi executado da seguinte maneira: (i) leitura e apresentação do texto de orientação do teste; (ii) aplicação de um questionário pré-teste; (iii) condução do teste aplicando o cenário sem a interação com o aplicativo; (iv) condução do teste aplicando o cenário com a interação com o aplicativo; (v) aplicação do questionário pós-teste; (vi) agradecimento pela participação.

Para a execução dos testes, foi elaborado um cenário visando realizar o maior número possível de interações no aplicativo, em virtude da situação do paciente, em um único teste. O caso clínico do teste foi dado pelo seguinte texto: "O médico de plantão é chamado na enfermaria para avaliar o paciente Oswaldo, que estava desacordado. Ao encontrar o senhor Oswaldo desacordado, o médico o chama e ele não responde. Então, o médico checa o pulso carotídeo e percebe que este está ausente. Detectando que o paciente está em parada cardiorrespiratória, solicita-se à equipe de enfermagem o início das medidas do protocolo ACLS".

Antes da execução de cada teste, foi aplicado o questionário pré-teste para a coleta de informações de cada participante, tais como: dados pessoais; dados relativos à 
qualidade do protocolo (por exemplo, formação profissional, tempo de experiência, conhecimento do protocolo ACLS, experiência com RCPs etc.); dados relacionados à qualidade de uso do aplicativo (experiência com computadores/celulares e com aplicativos com o mesmo objetivo do Stay Alive). Posteriormente ao teste, foi aplicado o questionário pós-teste, visando investigar a aceitação do aplicativo segundo a opinião dos participantes do estudo. Para alcançar este objetivo, foi utilizado o modelo TAM.

$\mathrm{O}$ modelo TAM se baseia em dois pilares principais ligados à crença: utilidade percebida e facilidade de uso percebida. A utilidade percebida é a medida que uma pessoa acredita que o uso de um sistema particular pode melhorar o seu desempenho. Já a facilidade de uso percebida é a medida que uma pessoa acredita que o uso de um sistema será livre de esforço (SILVA; DIAS, 2007). Para a elaboração do questionário pós-teste, baseado no TAM, optou-se por utilizar uma escala Likert de cinco pontos, com respostas variando de "discordo totalmente" a "concordo totalmente". Foram utilizadas 14 questões (Quadro 1), no formato de afirmações, com foco nas métricas previstas no TAM: utilidade percebida e facilidade de uso percebida.

Quadro 1 - Questionário pós-teste. Fonte: Os autores.

\begin{tabular}{|c|c|}
\hline Foco em & Questão \\
\hline \multirow{6}{*}{ Utilidade } & 1 - Todas as funções do aplicativo estão de acordo com a ação de meus socorristas \\
\hline & $2-\mathrm{O}$ aplicativo possui as funções do protocolo ACLS \\
\hline & $3-\mathrm{O}$ aplicativo me ajudou a seguir o protocolo ACLS \\
\hline & 4 - Senti falta de uma função no aplicativo \\
\hline & 5 - Eu acho que o aplicativo contribui para aumentar a taxa de sucesso de uma RCP \\
\hline & $6-\mathrm{O}$ aplicativo é útil aos demais profissionais \\
\hline \multirow{8}{*}{ Facilidade } & 7 - Achei fácil utilizar o aplicativo \\
\hline & 8 - Cada ação no aplicativo foi rápida de ser executada \\
\hline & 9 - Precisei utilizar o tutorial para aprender a usar o aplicativo \\
\hline & 10 - A equipe de socorristas aprovou o uso do aplicativo \\
\hline & 11 - Ocorreu algum erro durante a execução do aplicativo \\
\hline & 12 - Você utilizou o aplicativo antes de executar o teste \\
\hline & $13-$ A interface do aplicativo é intuitiva \\
\hline & $14-\mathrm{O}$ aplicativo é lento ou deixa o aparelho lento \\
\hline
\end{tabular}

Em consonância com as diretrizes do TAM, uma vez aplicados os questionários pré e pós-teste, uma análise de dados foi realizada a fim de identificar as opiniões dos participantes e a efetividade do aplicativo no apoio ao ensino do protocolo ACLS.

\section{RESULTADOS}

Inicialmente, após a aplicação do pré-teste, pode-se concluir as seguintes informações sobre os participantes: todos são do sexo feminino, com faixa etária variando de 21 a 27 anos; nenhum participante possuía experiência profissional; todos já presenciaram uma PCR; a maioria (sete) não possuía experiência com RCP; a minoria (dois) declarou não possuir experiência com computadores e seis informaram que possuem experiência de pelo menos 10 anos; todos possuem celulares há, pelo menos, sete anos; nenhum participante conhece ou utilizou qualquer aplicativo para auxiliar uma RCP. De modo geral, constatou-se que os participantes eram estudantes ainda inexperientes com relação à condução de uma RCP e aprendizes do protocolo, apresentando dúvidas e incertezas sobre qual ação tomar para cada situação. As Figuras 2 e 3 ilustram as respostas dos participantes no questionário pós-teste.

De modo geral, os dados obtidos referentes à utilidade do aplicativo revelam uma aprovação da maioria dos participantes. Em contrapartida, os dados relacionados à 
facilidade de uso apresentam uma variação nas respostas. Todos os participantes concordaram totalmente ou parcialmente que o aplicativo é fácil de ser utilizado (questão 7), mesmo que dois usuários tenham respondido que precisaram de ajuda para aprender a usar o aplicativo (questão 9). É importante citar que com base nas respostas obtidas na questão 12, observou-se que nem todos os participantes eram experientes no uso do aplicativo, sendo que todos instalaram e o conheceram no dia do teste.

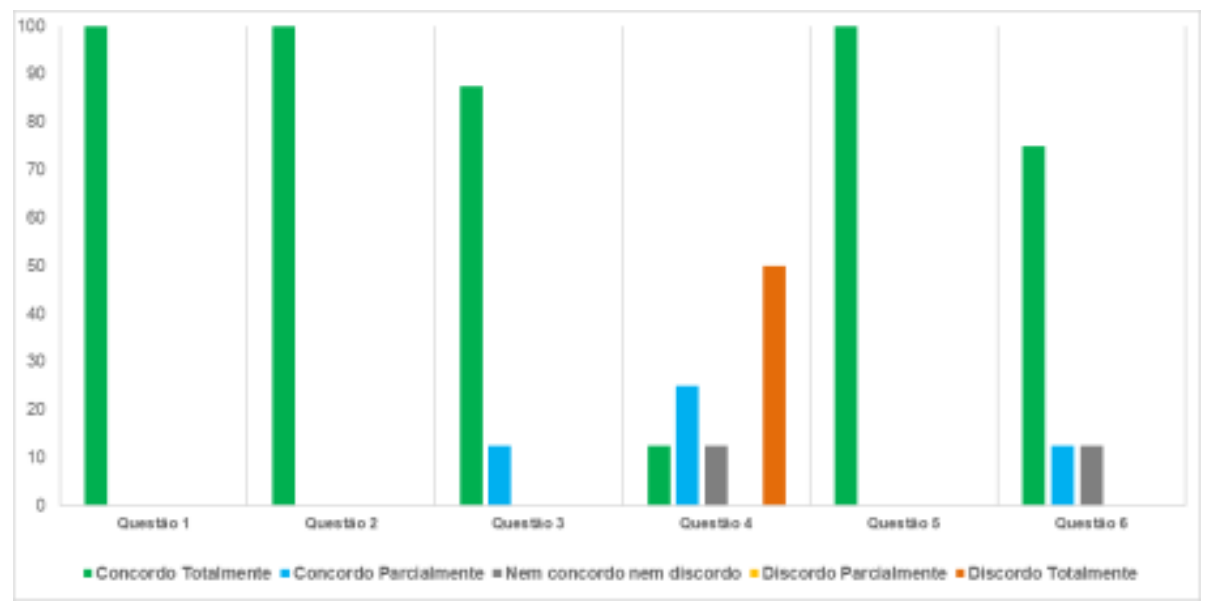

Figura 2 - Opinião dos participantes sobre a utilidade percebida. Fonte: Os autores.

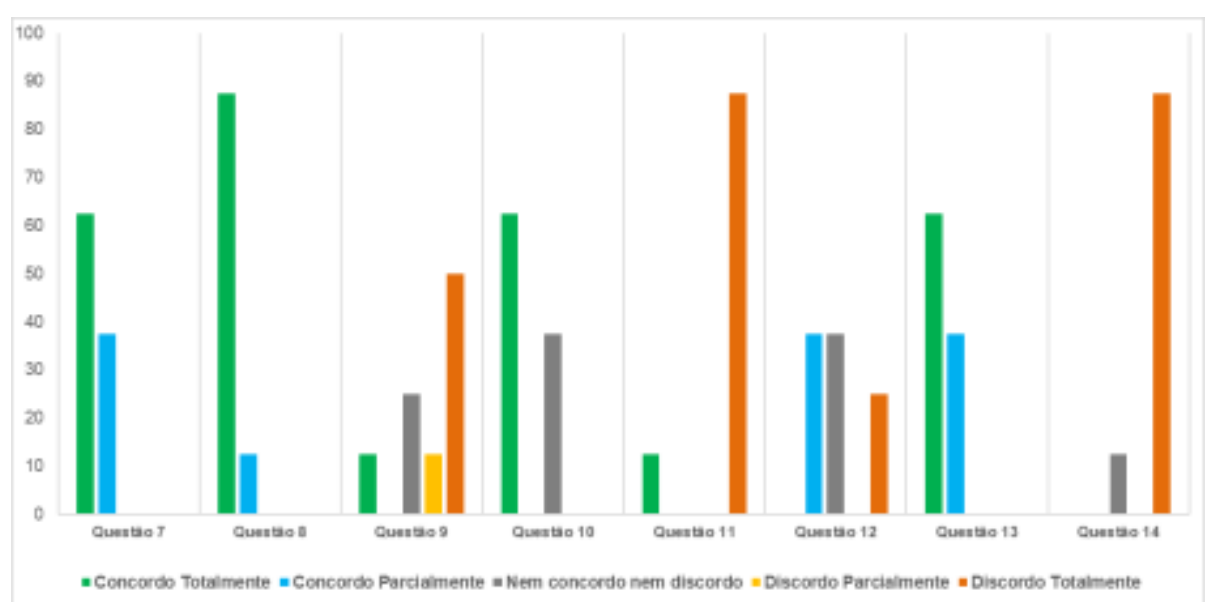

Figura 3 - Opinião dos participantes sobre a facilidade de uso percebida. Fonte: Os autores.

As questões 1,2 e 5 alcançaram unanimidade em suas respostas, e se referem ao auxílio que o aplicativo forneceu ao usuário no que tange à tomada de decisão do protocolo. A questão 4, referente à falta de alguma função no aplicativo, teve certa divergência nas respostas. Os participantes foram questionados a respeito das funções que sentiram falta e, em alguns casos, notou-se que o aplicativo já possuía aquele determinada função, todavia, devido à pouca familiaridade com o aplicativo, os usuários não relacionaram alguns itens da interface gráfica com a respectiva função. A questão 9, referente à necessidade de utilizar o tutorial para conseguir interagir com o aplicativo, também teve divergência nas respostas. Como os usuários não utilizaram o aplicativo antes do teste, muitos se sentiram inseguros para utilizá-lo pela primeira vez. Contudo, ao indagá-los sobre as respostas, os participantes revelaram que os próprios participantes trocavam informações de funcionamento do aplicativo entre si, o que pode justificar a variação nas respostas obtidas. 
O Quadro 2 ilustra a comparação dos cenários com e sem o uso do aplicativo para todos os participantes. Esta comparação é referente à quantidade de ações erradas em relação ao protocolo ACLS e à quantidade de ações cujo tempo de atraso superou a margem de erro estipulada de 20 segundos (ações com atraso). A única variável que diferencia os cenários é a presença do aplicativo.

Quadro 2 - Comparação dos cenários com e sem o aplicativo. Fonte: Os autores.

\begin{tabular}{|c|c|c|c|c|}
\hline & \multicolumn{2}{|c|}{ Erros cometidos } & \multicolumn{2}{c|}{ Ações com atraso } \\
\hline & Sem app & Com app & Sem app & Com app \\
\hline Teste 1 & \multicolumn{4}{|c|}{ Descartado } \\
\hline Teste 2 & \multicolumn{4}{|c|}{ Descartado } \\
\hline Teste 3 & 2 & 1 & 0 & 0 \\
\hline Teste 4 & 1 & 2 & 1 & 0 \\
\hline Teste 5 & 2 & 3 & 2 & 2 \\
\hline Teste 6 & 0 & 0 & 1 & 0 \\
\hline Teste 7 & 4 & 1 & 3 & 0 \\
\hline Teste 8 & 4 & 1 & 0 & 0,83 \\
\hline Média & 2,17 & 1,33 & 1,17 & \\
\hline
\end{tabular}

O participante do teste 1 foi descartado, pois seu teste foi utilizado como piloto para fins de verificação de possíveis problemas no cenário elaborado. $O$ teste do participante 2 também foi descartado, pois suas ações foram incoerentes com 0 protocolo na maioria das atividades. A confirmação de que este participante não sabia realizar o protocolo foi corroborada com as respostas obtidas no questionário pré-teste. O Quadro 2 mostra que a presença do aplicativo possibilitou uma melhora nos resultados. Inclusive, nota-se que, para três casos, houve uma diminuição da quantidade de erros.

Em dois casos (testes 4 e 5) houve aumento da quantidade de erros. Os erros adicionais se deram pela não aplicação da amiodarona (droga) e do choque. No entanto, estes mesmos erros não aconteceram na primeira rodada (cenário sem aplicativo). Este incremento pode ser atribuído ao nervosismo do participante, a algum problema de usabilidade do aplicativo ou à falta de familiaridade com o aplicativo. Para os testes $7 \mathrm{e}$ 8 , os resultados também foram referentes à aplicação dos mesmos itens (amiodarona e choque), porém, de uma forma positiva. Sem o uso do aplicativo, o usuário administrou choque em um momento onde ele não deveria fazê-lo. Com o auxílio do aplicativo, nenhum usuário administrou choque erroneamente. Nota-se que, de modo geral, a quantidade de erros cometidos no cenário com o aplicativo foi inferior ao cenário sem o aplicativo.

Em três dos oito testes realizados, os usuários realizaram alguma ação com o auxílio do aplicativo que haviam esquecido de fazer na sua ausência. Uma das ações em que a presença do aplicativo teve um impacto considerável foi a segunda aplicação da adrenalina. Metade dos participantes esqueceu de aplicar a segunda dose sem o aplicativo. Dentre os que se lembraram, apenas um teve um tempo próximo ao indicado pelo protocolo. Os outros dois que se lembraram, aplicaram a dose com mais de 20 segundos de atraso. Em outros testes, os usuários não aplicaram a segunda dose da adrenalina, provavelmente por não terem contabilizado o intervalo manualmente. Por fim, $100 \%$ dos participantes se lembraram de realizar a aplicação da segunda dose no teste com a presença do aplicativo. 


\section{CONSIDERAÇÕES FINAIS}

Esta pesquisa abrangeu o desenvolvimento de um aplicativo para apoiar a aprendizagem do protocolo ACLS, uma vez que a parada cardiorrespiratória é uma das causas mais comuns de mortes no mundo. Os testes realizados objetivaram, sobremaneira, verificar a efetividade de uso do aplicativo, e os participantes voluntários concordaram que este foi útil para auxiliar a execução do protocolo, além de fácil de usar. Sobre os dados obtidos nos testes foi concluído que o número de erros cometidos com a presença do aplicativo foi inferior à quantidade de erros cometidos sem a sua presença para a maioria das atividades monitoradas. Ainda sobre os resultados, foi constatado que, com o auxílio do aplicativo, $100 \%$ dos participantes executaram a ação de aplicação de adrenalina corretamente, sendo que no mesmo cenário apenas $50 \%$ dos participantes executaram esta tarefa corretamente sem o auxílio do aplicativo.

Outro resultado importante é a lembrança que o aplicativo trouxe para a realização de algumas ações. Isto foi observado na execução correta da atividade apenas no cenário onde o aplicativo está presente e a ausência da mesma ação no cenário sem o aplicativo. Isto ocorreu tanto para a aplicação dos choques quanto das drogas, que são funções diretamente relacionadas com o auxílio fornecido pela interação com o aplicativo.

De modo geral, ao relacionar os dados obtidos a partir dos testes, de seus questionários e da observação das ações conduzidas nos testes, conclui-se que o aplicativo foi eficaz em sua função de auxílio à RCP seguindo as diretrizes do protocolo ACLS. Como contribuição prática desta pesquisa, o aplicativo desenvolvido encontra-se disponível nas plataformas Android e iOS gratuitamente. Como trabalhos futuros, devese elaborar uma nova versão do aplicativo analisando a viabilidade de uma nova interface para minimizar ainda mais a quantidade de erros cometidos pelo usuário. Em seguida, um novo teste deverá ser elaborado e executado, sobretudo, com uma amostra maior, visando à aplicação de modelos estatísticos para testes de hipóteses. Um estudo sobre a influência das emoções dos participantes na execução do teste também deverá ser realizado.

\section{REFERÊNCIAS BIBLIOGRÁFICAS}

ABOUT CARDIAC ARREST. Disponível em: <http://www.heart.org/HEARTORG/Conditions/More/CardiacArrest/About-CardiacArrest_UCM_307905_Article.jsp\#.WV071oTyuUk>. Acesso em 5 jul. 2017.

AMERICAN HEART ASSOCIATION. Highlights of the 2015 American Heart Association guidelines update for CPR and ECC. Dallas, USA: American Heart Association, 2015.

BARBOSA, M. L. K. et al. Uma solução m-Health para apoio à educação em saúde com foco na mudança de comportamento para hábitos saudáveis. RENOTE, v. 16, n. 2 , p. 291-300, 2018.

BROOKS, S. C. et al. Part 6: Alternative techniques and ancillary devices for cardiopulmonary resuscitation. Circulation, v. 132, n. 18 suppl 2, p. S436-S443, 2015.

DANE, F. C. et al. In-hospital resuscitation: association between ACLS training and survival to discharge. Resuscitation, v. 47, n. 1, p. 83-87, 2000. 
DAVIS, F. D. et al. User acceptance of computer technology: a comparison of two theoretical models. Management Science, Ann Arbor (MI), v.35, n.8, p.982-1003, 1989.

DINH, H. T. et al. A survey of mobile cloud computing: architecture, applications, and approaches. Wireless Communications and Mobile Computing, v. 13, n. 18, p. 1587$1611,2013$.

HAYES, C. W. et al. Residents feel unprepared and unsupervised as leaders of cardiac arrest teams in teaching hospitals: a survey of internal medicine residents. Critical Care Medicine, v. 35, n. 7, p. 1668-1672, 2007.

HAZINSKI, M. F.; FIELD, J. M. American Heart Association guidelines for cardiopulmonary resuscitation and emergency cardiovascular care science. Circulation, v. 122, n. Suppl, p. S639-S946, 2010.

ISBYE, D. L. et al. Disseminating cardiopulmonary resuscitation training by distributing 35000 personal manikins among school children. Circulation, v. 116, n. 12, p. 1380-1385, 2007.

KURRCK, M. M. et al. Cardiac arrest in the OR: how are our ACLS skills?. Canadian Journal of Anaesthesia, v. 45, n. 2, p. 130, 1998.

LIANG, X. et al. Effect of mobile phone intervention for diabetes on glycaemic control: a meta-analysis. Diabetic Medicine, v. 28, n. 4, p. 455-463, 2011.

MACIEL, J. D. et al. Proposta de uso de um aplicativo para auxílio ao processo de ressuscitação cardiopulmonar. Anais do X Computer on the Beach, p.199-208, 2019.

MEANEY, P. et al. Cardiopulmonary resuscitation quality: improving cardiac resuscitation outcomes both inside and outside the hospital: a consensus statement from the American Heart Association. Circulation, v. 128, n. 4, p. 417-435, 2013.

RINGH, M. et al. Mobile phone technology identifies and recruits trained citizens to perform CPR on out-of-hospital cardiac arrest victims prior to ambulance arrival. Resuscitation, v. 82, n. 12, p. 1514-1518, 2011.

SANTOS, L. C. et al. Aprendizagem baseada em projetos na informática em saúde: desenvolvendo aplicativos com App Inventor. RENOTE, v. 17, n. 1, p. 42-51, 2019.

SIEGEL, J. et al. A feasibility pilot using a mobile personal health assistant (PHA) app to assist stroke patient and caregiver communication after hospital discharge. mHealth, v. 2, n. 8, 2016.

SILVA, P. M.; DIAS, G. A. Teorias sobre aceitação de tecnologia: por que os usuários aceitam ou rejeitam as tecnologias de informação? BJIS, v.1, n.2, p.69-91, 2007.

SONG, J. et al. Application discoverability and user satisfaction in mobile application stores: An environmental psychology perspective. Decision Support Systems, v. 59, p. 37-51, 2014. 